\title{
A WSQ-based mobile peer assessment approach to enhancing university students' vocal music skills and learning perceptions
}

\author{
Chenchen Liu, Ping Wan \\ Wenzhou University, China \\ Yun-Fang Tu \\ Fu Jen Catholic University, Taiwan \\ Kai Chen, Youmei Wang \\ Wenzhou University, China
}

\begin{abstract}
Peer assessment has been regarded as an effective learning strategy in art education, such as in music, dance and art design. For music education, technology-supported peer assessment makes it easier for learners to reflect on their learning performance. However, the process of reflection needs solid and systematic theoretical knowledge. In terms of vocal music, which develops students' singing skills, it is difficult for learners to compare their own works with those of others because of a lack of sufficient theoretical knowledge. Therefore, a WSQ (watch-summary-question)-based mobile peer assessment approach was used to help learners reflect based on their theoretical knowledge with the support of WSQ learning sheets. To investigate the effectiveness of the approach, an experiment was carried out in a Chinese university. The experimental group $(N=22)$ learned with the WSQ approach, whereas the control group $(N=22)$ adopted a mobile peer assessment approach without WSQ. Vocal music skills, learning attitude and learning motivation were assessed. The experimental results indicate that the approach effectively enhanced the students' vocal music skills but did not improve their learning motivation or attitude. In addition, a higher correlation between teacher scoring and peer scoring was found for the experimental group.
\end{abstract}

Implications for practice or policy:

- Technology has a great potential in supporting art education and integrating technology into vocal music education should follow the rules of music education.

- Developing students' reflective thinking skills in vocal music education is challenging, but attainable; it needs considered instructional design and sustained efforts from students.

Keywords: watch-summary-question (WSQ) strategy, peer assessment, vocal music education, mobile learning, reflective thinking

\section{Introduction}

Vocal music is one of the courses in which skill acquisition is required. Differing from instruction in traditional subjects emphasising, memorising, understanding and applying knowledge, one of the characteristics of vocal music education is that it aims at improving students' singing performance and skill development (Neokleous, 2015). The communication between teachers and students is mainly considered as direct experience, emphasising the importance of students' deliberate follow-up practice after learning (Ericsson et al., 1993). During the teaching of vocal music, teachers demonstrate singing and illustrate the phonation techniques for students. Students' singing performance can be enhanced through listening, mimicry and deliberate practice (Gaunt, 2008). According to the cognitive theory of musical education, only continuous and repeated practice can effectively enhance students' musical skills (Griffiths \& Woolf, 2009). Thus, effective learning strategies are needed to promote students' reflection during the process of deliberate practice, with the aim of maintaining a high level of motivation for skills enhancement (Lehmann, 2015). 
Similar to the majority of music courses, vocal practice is a process of art creation and re-creation, where one-to-one tuition forms a core part of the vocal music teaching (Demorest et al., 2018). However, largeclass and small-group teaching are often adopted in many schools because of the limited number of teachers. The traditional teaching format of vocal music is a one-way flow whereby teachers use oral teaching to deliver direct experiences to students (Griffiths \& Woolf, 2009). This format may lead to a lack of communication, interaction and reflection between teachers and students because of the passive learning experience (D. Li, 2015). Better teaching formats for students are urgently needed so that the students can receive personalised guidance and support as well as sufficient opportunities for reflection. Peer assessment (PA), an interactive assessment conducted by peers during the learning process, might be helpful for students to communicate, interact and reflect in vocal music courses (Topping, 1998). When conducting PA in vocal music courses, students' performance will be recorded in a video-based format for interactive assessment. During the process of commenting on others' work and receiving comments from peers, learners, who can switch their identities between evaluator and learner, can be prompted to reflect on their performance (Hobbs, 2006). On the one hand, students can act as reviewers to observe peers' vocal performance from the viewpoint of teachers, in particular comparing others' performance with their own during reflection. On the other hand, in order to be evaluated positively by others, students in vocal music courses may devote more efforts towards having an exceptional performance (Tsivitanidou et al., 2011; Wu \& Kao, 2008). However, PA also has limitations; for instance, students may feel confused by complex comments, they may feel frustrated with the overlong and ineffective assessment time, they may be not willing to comment on others or they may not take others' comments seriously (Chien et al., 2020; Lai \& Hwang, 2015). All of these limitations will hinder communication between teachers and students, leading to a lack of interaction between them. For vocal music courses, which emphasise direct experience, integrating teaching strategies could benefit students to have more space for reflection with the support of instant and personalised guidance (Tsivitanidou et al., 2011; Wu \& Kao, 2008). Technology-supported PA has been shown to enhance learning effectiveness in many courses (Liu \& Lin, 2007; Tsai \& Liang, 2009; Tseng \& Tsai, 2007). With the development of mobile technology, technology-supported PA has revealed huge potential for cultivating and improving students' higher order thinking abilities, such as collaborative learning, communication and critical thinking (Hwang et al., 2014). Mobile PA has been explored in artrelated courses, such as dancing performance (Hsia et al., 2019), musical theatre performance (I. C. Chen et al., 2020) and artwork design (Lai \& Hwang, 2015). Scholars have indicated that the combination of PA and learning strategies has great potential for assisting students in further evaluating both their own and their peers' learning processes, with the aim of enhancing their learning effectiveness (Santagata et al., 2007; Wu \& Kao, 2008).

Vocal music courses have applied PA as teaching strategies, in particular for enhancing students' ability to detect errors in their own and in their peers' performances, as well as the ability to self-evaluate their skills (Thornton, 2008). Studies have indicated that students' participation in PA and self-assessment improves their singing performance skills (Swaffield, 2011). Furthermore, high-quality peer evaluation given by students depends on their mastery of vocal techniques and music theory (Demorest et al., 2018). In general, training in vocal techniques and performance has been taken seriously in vocal music courses (Svec, 2018). However, students are not able to conduct objective evaluations of others' singing work without systematic and in-depth mastering of theoretical knowledge in vocal music during the learning process.

Scholars have indicated that, to enable students to make reflections on their own works, it is important to help them think in depth when acquiring theoretical knowledge. That is, integrating proper strategies into activities could be a solution for enhancing students' engagement in class and the depth of their reflections (Yilmaz, 2017). The watch-summary-question (WSQ) strategy has been recognised as effective in guiding students to think in-depth during the learning process (Hsia et al., 2019). WSQ was originally proposed by Kirch (2012) to guide students to take notes, summarise and propose questions based on their observations of the learning content as well as their interpretation and organisation of the knowledge they had acquired. WSQ has often been introduced in flipped classrooms to organise and promote pre-class activities (Hsia et al., 2019; Lin, et al., 2019). WSQ has the potential to engage learners in thinking deeply since summarising and questioning require them to organise their knowledge and ideas from the lower cognitive levels to the higher thinking levels (Brown \& Walter, 2014). Therefore, WSQ has been introduced into PA with the aim of guiding students to pay attention to the main idea while observing teaching and other videos, as well as guiding them to summarise and pose questions for the enhancement of vocal techniques and performance. In order to investigate the influences of the strategy on students' vocal techniques, performance and learning attitude, three main research questions were addressed as follows: 
1. Does WSQ-based mobile PA effectively enhance students' vocal musical performance?

2. Does WSQ-based mobile PA effectively enhance students' learning attitude?

3. What is the perceived usefulness of WSQ-based mobile PA for students in the experimental group?

\section{Literature review}

\section{Technology-enhanced vocal music courses}

In conventional vocal music courses, teachers give a singing demonstration and students imitate and practice repeatedly. Recently, vocal music courses have undergone great changes because of the development of information and communication technology. Combined with the ever-changing technology, vocal music education aims to increase the active participation of students in all of the learning activities (Z. Li, 2017). Studies have introduced different teaching strategies to assist students in enhancing their vocal music performance and related vocal music theories in various circumstances (Svec, 2018). For instance, Hewitt (2011) combined the recorded voice model with self-evaluation to enhance students' melodic accuracy, tone production and overall performance. Paney and Kay (2015) used computer games to assist students in enhancing their pitch-matching skills. Z. Li (2017) integrated Azur-PaaS (a learning platform) with learning, communication and evaluation modules in vocal music courses to promote student learning interest and participation. It can be inferred that introducing diverse technology into music education is promising, especially for vocal music education, which requires both accuracy and artistic performance.

Although the introduction of technology into vocal music education is a valuable topic of discussion and has brought about changes in the roles of teachers and students in the teaching process, the simple introduction of technology into vocal music education does not guarantee an improvement in the quality of such education. It is, therefore, necessary to introduce some targeted teaching strategies. According to the literature, feedback is the most common intervention used in vocal music teaching. Face-to-face feedback in classes, computerised feedback after classes, or the combination of both can improve students' vocal music performance (Svec, 2018). Some studies have also pointed out that different types of teacher feedback (generic or more specific) can affect the enhancement of students' vocal music performance (Rutkowski \& Miller, 2003). If students' vocal musical performance is determined only by the teacher's individual marks, this cannot fully evaluate and promote students' vocal music learning, and it is difficult for them to have the opportunity to reflect on and improve their vocal musical techniques and performance.

Therefore, this study was conducted in a vocal music course for university students with PA using mobile technology, allowing students to watch videos of the teacher's teaching and the singing of other students at any time. There is great potential for them to enhance their vocal musical performance through high-quality self-reflection and peer assessment (Gallo, 2019).

\section{PA}

PA is a potential learning strategy that engages students in knowledge construction and skill development by understanding teachers' rubrics for assessing and learning from and reflecting on peers' work through reflection (Boud et al., 1999; Carlson \& Berry, 2008; Matsuno, 2009; Tseng \& Tsai, 2010). PA enables students to think critically and manage their own learning status. Moreover, students' analytical abilities, which will be inspired while reviewing peers' work, can assist them in reflecting on their work and enhancing their task performance (I. C. Chen et al., 2020; Searby \& Ewers, 1997).

The effectiveness of PA has been validated in many courses, such as science, English, art performance and teacher training. For instance, Tseng and Tsai (2007) used PA in learning activities in a high school science curriculum and found that students' learning achievements improved significantly. Hwang et al. (2014) found that game-based PA significantly enhances high school students' academic performance, learning motivation and problem-solving skills. Tai et al. (2015) used PA in English composition and found that students' writing skills improved. C. Chang and Lin (2019) conducted experimental research related to mobile-based PA and explored its influences on students' speaking abilities in English as a Foreign Language. Furthermore, some researchers have used PA in art performance-related activities. For example, C.-C. Wu and Kao (2008) implemented a web-based PA system using video streaming technology in a pre- 
service teacher training program. I. C. Chen et al. (2020) integrated an online PA learning platform into a university-level musical theatre course with the aim of exploring the influences of PA modes including peer scoring, peer commenting and peer scoring and peer commenting on students' learning. They found that peer scoring and peer commenting can enhance students' musical theatre performance better than peer scoring only and peer commenting only. Latukefu (2010) introduced PA into the singing session of a creative arts performance course in undergraduate studies in an Australian university. Their results showed that students can think critically about others' performance and then reflect on their own work if they perceive themselves as the facilitators of the PA.

Despite the success of PA in several courses, some researchers have pointed out the problems of this method. One of the problems is that students do not feel qualified to judge the work of their peers and are unwilling to participate in PA; thus, it is important to create a friendly learning environment for participation (Latukefu, 2010). Another is the lack of effective technical tools to provide instant feedback when organising the PA activities (Denton et al., 2008; P.-H. Wu et al., 2012). If students cannot immediately solve problems during learning, they may feel frustrated and lose interest (H.-R. Chen \& Huang, 2010). On the other hand, researchers have indicated the importance of guiding students to prepare for participating in PA activities (Clipa et al., 2011; Tseng \& Tsai, 2007). Hung et al. (2016) also pointed out that the strong correlation between peer and teacher assessment is largely determined by the learners' mastery of the underlying theoretical knowledge. Therefore, there is a need to integrate an effective guiding strategy with detailed rubrics into the learning design, with the aim of strengthening students' understanding of and preparation for PA activities.

\section{WSQ learning strategies}

In order to enhance PA activities, WSQ was introduced in the current study. Originally proposed by Kirch (2012), WSQ strategies have been widely applied in flipped learning activities, in which researchers have indicated their effectiveness in promoting learners' reflection on the learning process through being required to summarise and question based on the learning materials (Hsia et al., 2019). In addition, researchers have developed more strategies to facilitate reflection in the learning process based on WSQ, such as annotation, summarising, questioning (Lin et al., 2019) and annotation, reflection, questioning and interflow (Hsia et al., 2020). Brown and Walter (2014) confirmed the effectiveness of WSQ in promoting deep reflection and pointed out that self-assessment or PA is a cognitive process from the lower cognitive level to the higher thinking level and that integrating proper strategies such as WSQ to scaffold this process is needed. This research therefore used a WSQ-based mobile PA approach and integrated it into a vocal music course, with the aim of enhancing students' ability to conduct better assessment of their peers, while also enhancing their vocal musical performance.

\section{Method}

Based on WSQ (Kirch, 2012), the current study conducted an experiment in a vocal music course to investigate the influences of the WSQ-based mobile PA on students' vocal skills and learning perception.

\section{Participants}

The invited participants were 44 freshmen, who were 20 years old on average. All of them had learned vocal music for at least 1 year and they were taught by the same teacher. They were required to attend the weekly vocal music course for 5 weeks. The experimental group $(\mathrm{N}=22)$ used WSQ-based mobile PA, while the control group $(\mathrm{N}=22)$ used mobile PA without WSQ.

The participants' anonymity was protected by concealing their personal information during the research process. They knew that their participation was voluntary and that they could withdraw from the study at any time.

\section{Experimental procedure and learning activities}

The experiment was conducted in a Chinese University in October 2019 (see Figure 1 for the experimental process). Before starting the experiment, the teacher introduced Mosoteach (a learning management system for watching video and implementing PA) to the students of both groups. Thereafter, the students were 
required to fill in a learning attitudes questionnaire, and the teacher scored their singing performance. During the experiment, a 90-minute vocal music class was conducted each week for 5 weeks for both groups. After class, both the experimental and control groups were asked to record and upload their singing videos on the learning platform; during their practice they could watch the instructional video recorded by the teacher. The experimental group was required to complete five WSQ-based learning sheets based on the learning units and rate peers' work on Mosoteach. For the control group, students took notes using their own methods and rated peers' work after uploading their own singing videos. During the learning activities, five learning units (pitch accuracy, tonal centre, tempo, expression or phrasing and tone quality) of vocal music were conducted in order to improve students' vocal music performing skills. At the end of the 5week experiment, the students' vocal music performance and their learning attitudes were examined by three experienced vocal music teachers, and students then took part in a semi-structured interview.

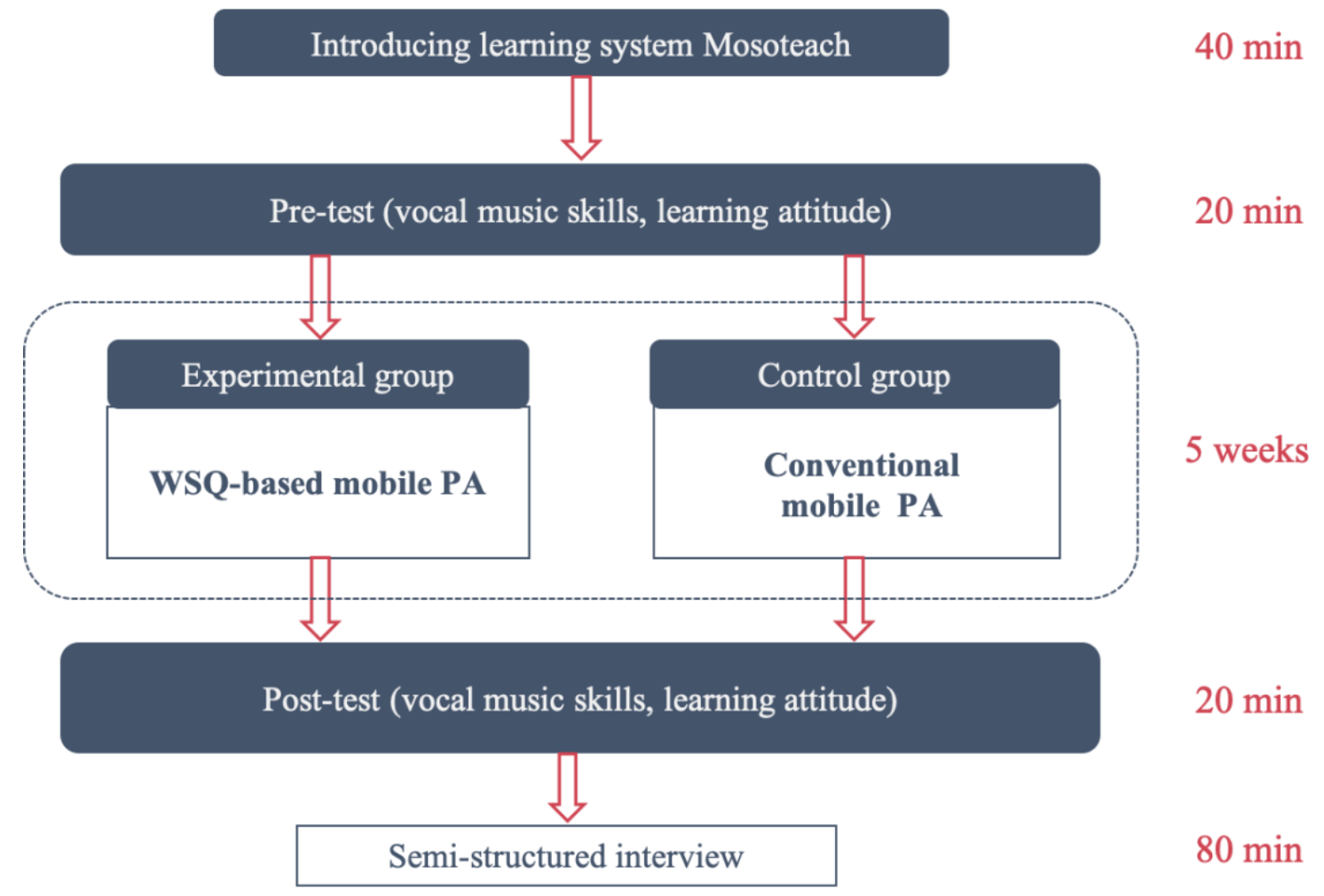

Figure 1. Experimental procedure

\section{WSQ-based mobile PA learning environment}

For this research, a WSQ-based mobile PA environment supported by Mosoteach (MosoInk, (https://www.mosoteach.cn/) was established to support a vocal music course, as shown in Figure 2. This environment includes course information, the module for providing PA and the module for receiving PA. The function of the course information is to provide a space for teachers to upload teaching videos and online WSQ-based learning sheets. The teaching videos provide the teacher's recorded lesson to explain the content of the lesson so that students can pre-read and review the classroom teacher's demonstration of vocal skills; the sheets allow students to take notes when watching the tutorial videos at any time. In the module for receiving PA, students can read assessments by peers and review their own recorded singing performance. Students can assess the performance of peers via the module for providing PA. Teachers can manage the PA in Mosoteach, which mainly involves reviewing the peer evaluations, correcting the scores of peers if they are not fair, uploading weekly assignments, posting teaching videos and supervising the learning status of students via the teacher interface. 


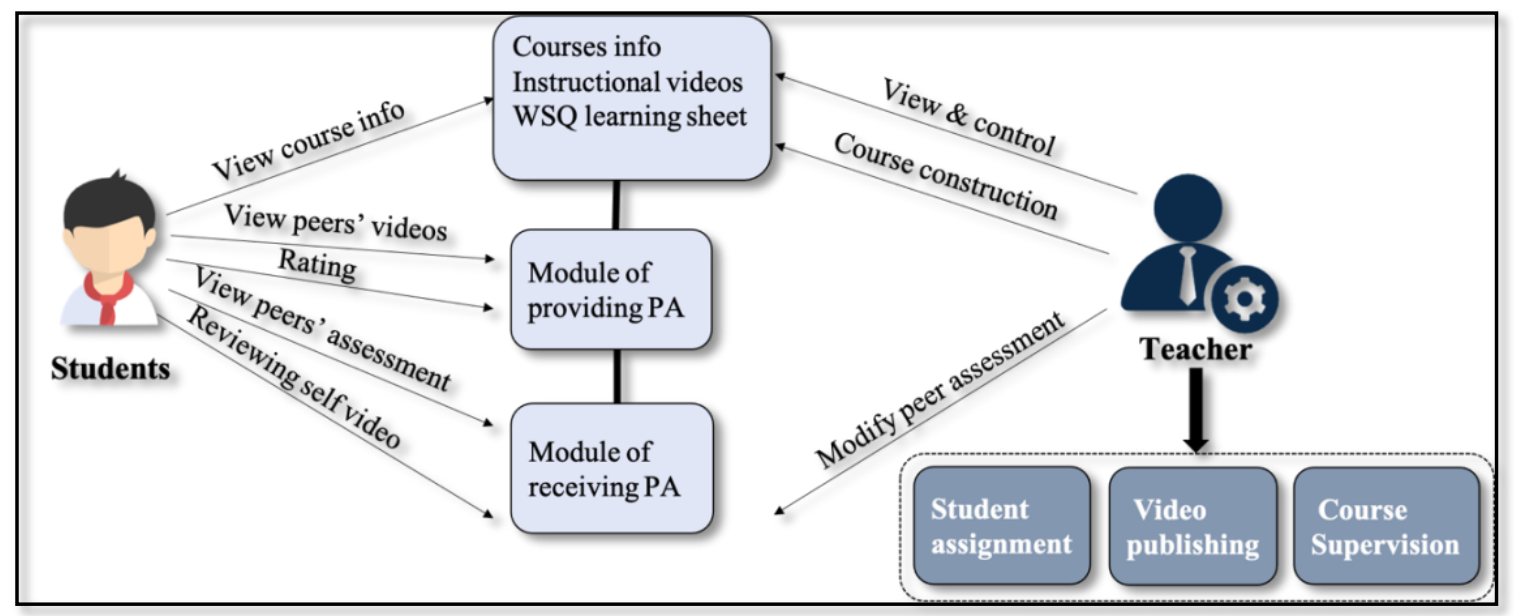

Figure 2. The structure of the learning system in the online PA

Figure 3 illustrates the students' learning interface. The course information is designed for students to gain access to the teaching videos and practise and reflect at any time.

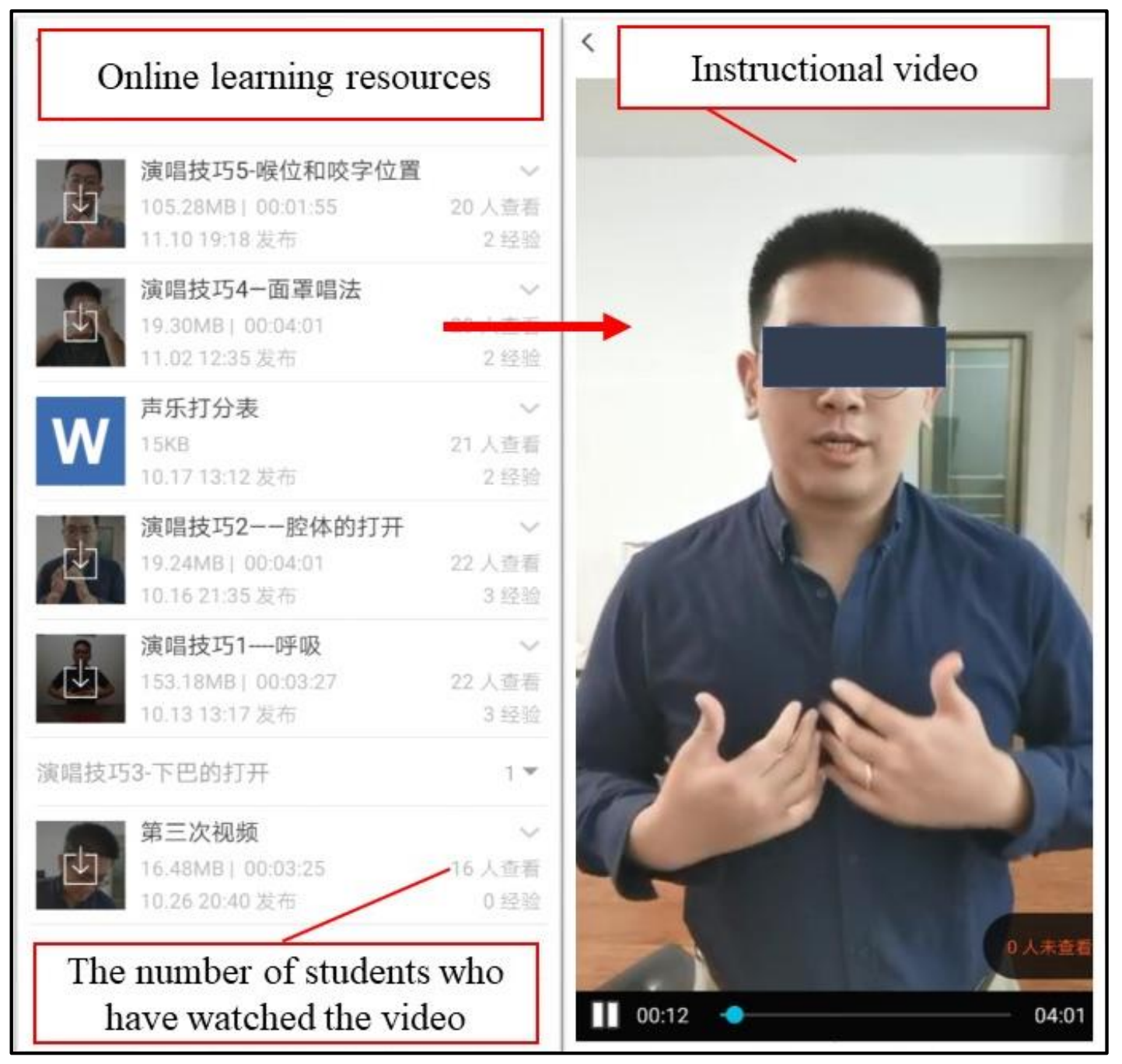

Figure 3. Interface of students' online mobile learning 
As shown in Figure 4, during the assessment process, each student was randomly assigned the work of five peers by Mosoteach for rating and commenting on anonymously according to the rubrics, while also reflecting on the strengths and weaknesses of their own work.

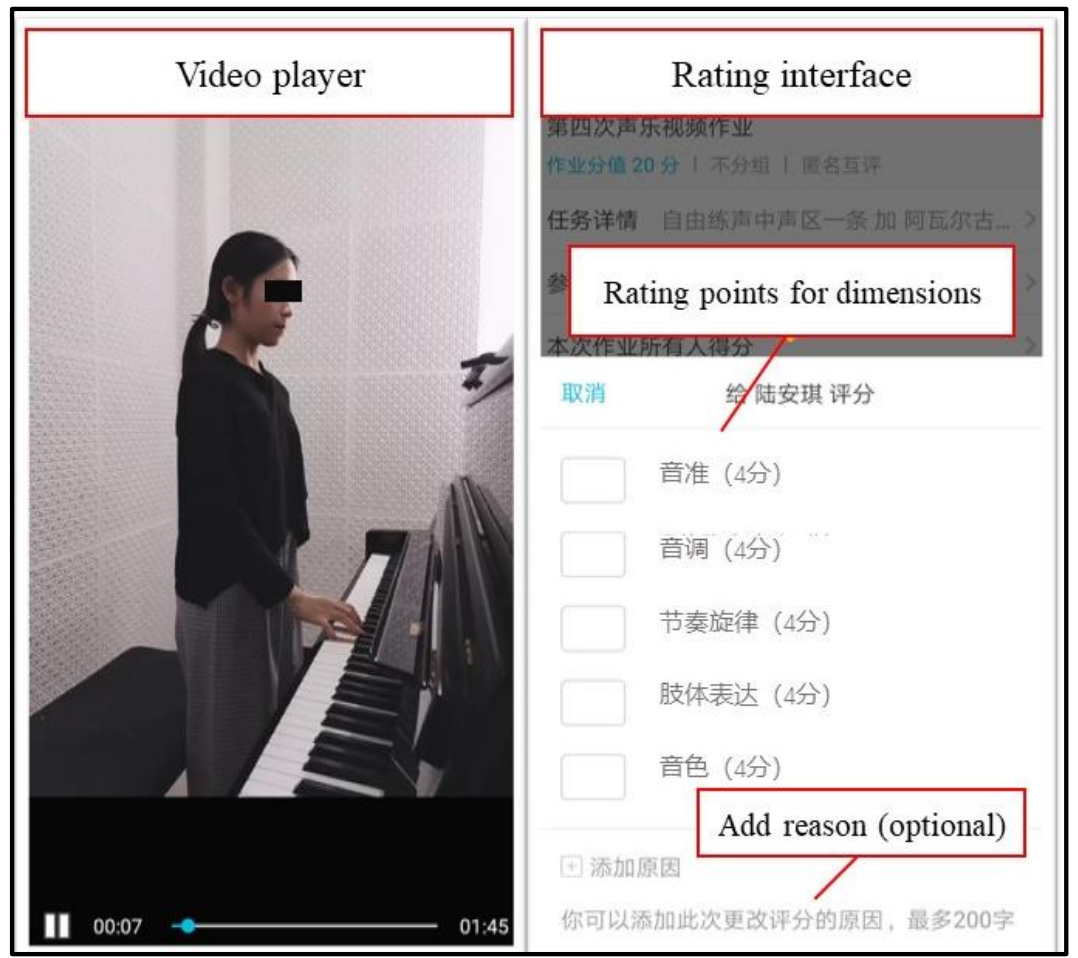

Figure 4: Interface for PA

For the interface of teacher assessment in Figure 5, teachers have access to the recorded videos of each student and the assessments by their peers. Teachers are able to view the rating score for each dimension in the rubrics and give comments.

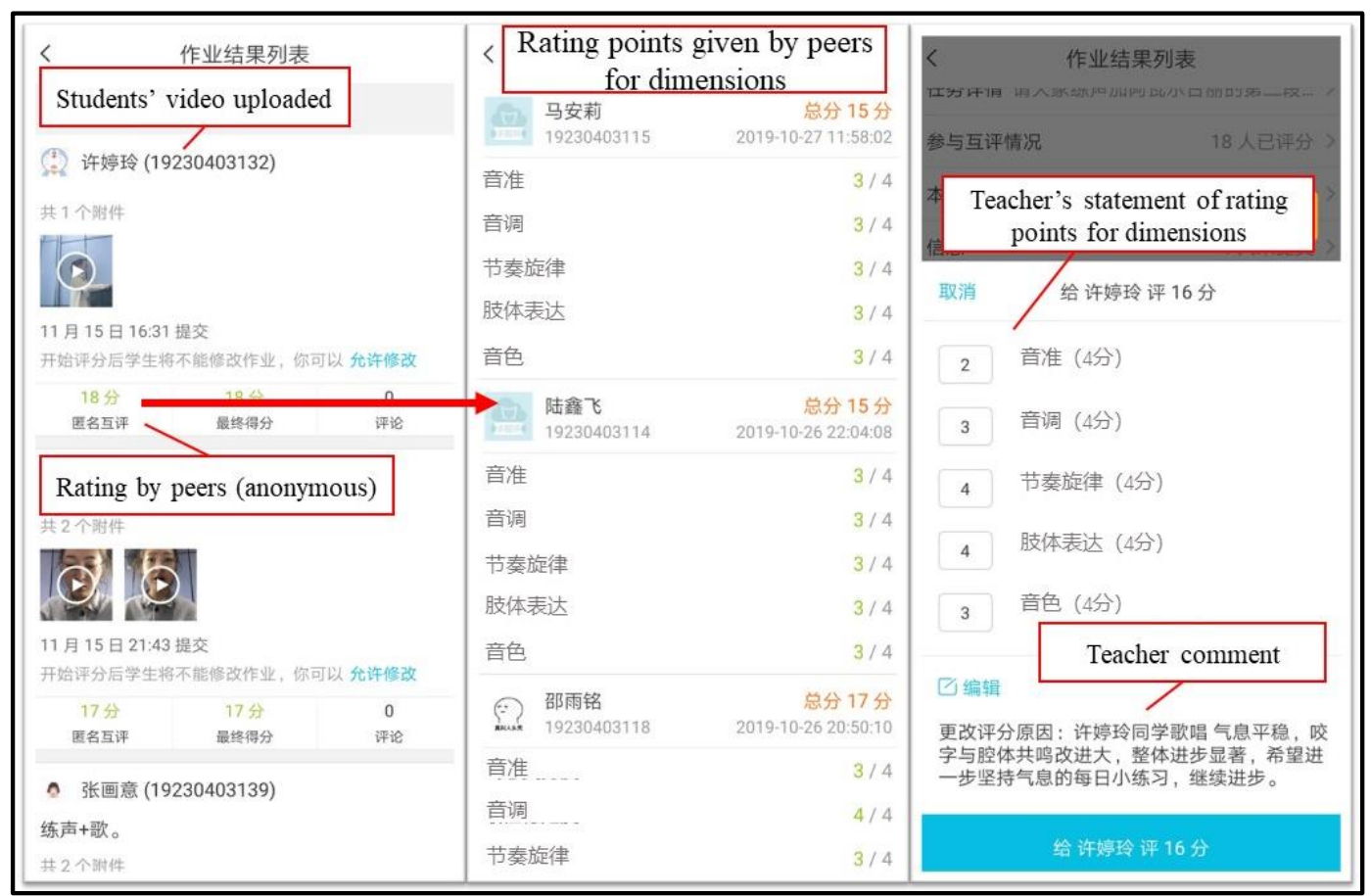

Figure 5. Interface for teacher assessment 
There are three sections in the WSQ learning sheet, as shown in Figure 6. First is the Watch section, which allows students to pause, fast-forward, or replay the essential part of the teaching videos and take notes if they have problems while watching the teacher's demonstration. Second is the Summarise section, which requires students to summarise the main points of the video. Third is the Question section, where students can pose questions relating to the content of the teaching videos. There were five WSQ learning sheets used during the learning process, and students were required to fill in and upload one sheet each week after watching the teaching videos.

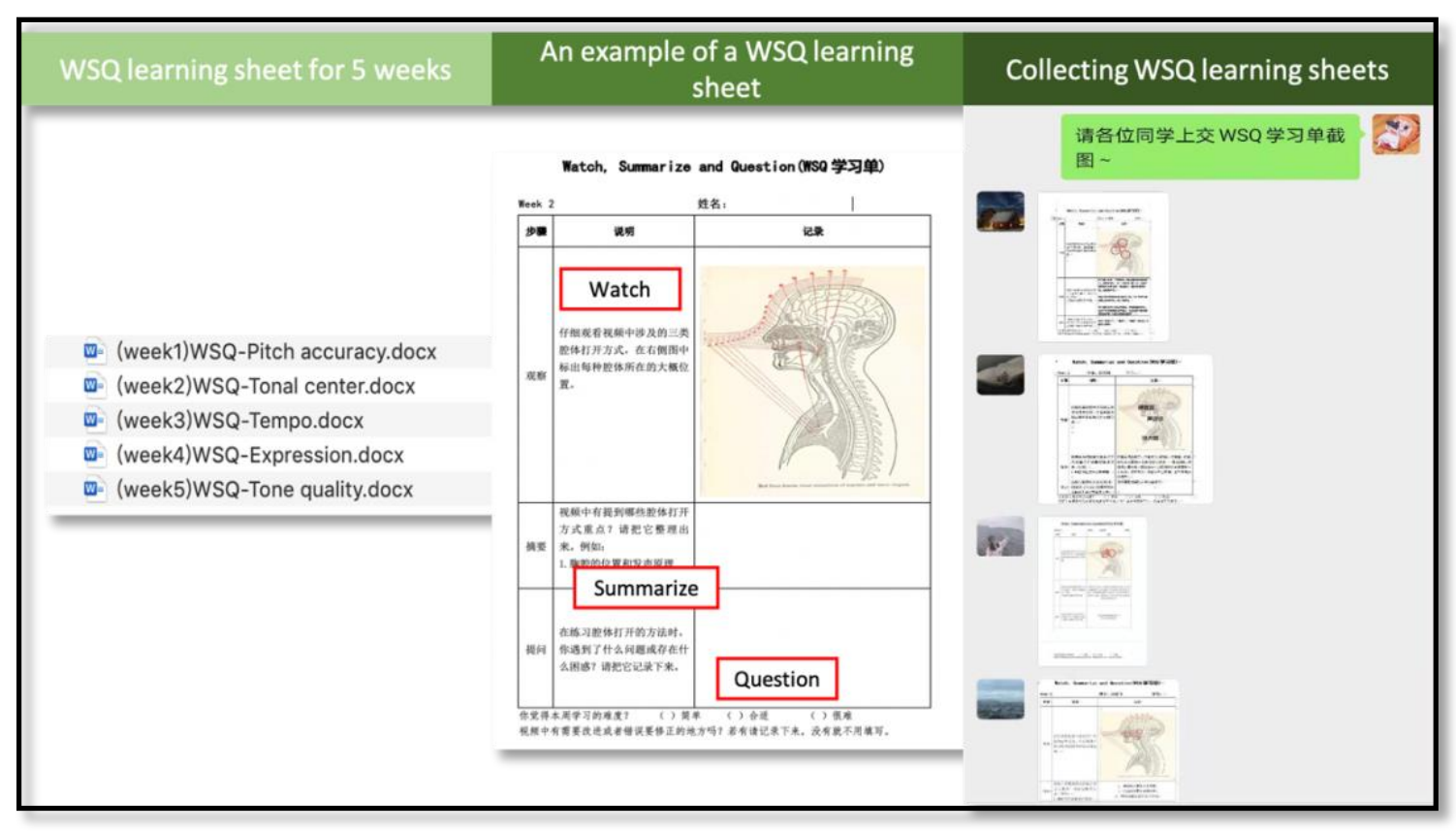

Figure 6. The WSQ-based learning sheet for learning activities

\section{Data collection}

The data collection methods adopted in this study were vocal music performance rating, a questionnaire on students' learning attitude and interviews on students' perceived usefulness of using the WSQ-based mobile PA.

\section{Data analyses}

With the intention of evaluating the students' vocal skills, we adapted the vocal music rubric of Gallo (2019); and three teachers who have many years of teaching experience of vocal music gave the scores . The details of the vocal music rubric are presented in the Appendix. It consists of five dimensions: pitch accuracy, tonal centre, tempo, expression or phrasing and tone quality. For each dimension, a 4-point scale was used to assess student performance, where 1 refers to poor performance and 4 refers to excellent performance. The average correlation coefficient of the ratings given by the three teachers on each item was between .68 and $.79(p<.01)$, indicating a significant correlation between them. The final score for each student's vocal music performance was determined by the average scores.

The questionnaire for learning attitude originated from the measurement method established by Hwang and Chang (2011). It consists of seven items, for example, "The vocal music course is a highly valuable course, and it is worth learning" and "I am interested in understanding more learning goals related to vocal music." A 7-point Likert scale was adopted, where 1 refers to strongly disagree and 7 refers to strongly agree; the Cronbach's alpha value of participants' internal consistency was .77.

At the end of the activities, students from both the experimental group and the control group took part in an 8-minute semi-structured interview in Chinese (translated by two of us - the first and second authors) to help us to understand the students' experience in the course. The interview outline and coding scheme were based on the method used by Hwang et al. (2009). There are seven questions, for example, "What is the 
difference between the current learning method and your previous learning experience? Please list and explain the knowledge and skills acquired during the learning process." (see the Appendix). The entire interview was recorded, and the content was transcribed verbatim. Two of us (the first and second authors) categorised the answers given by students. In case of disagreement between them, they reviewed the categories together to reach a consensus. The kappa value of the coding results of the two researchers was .91, showing high consistency (Lavrakas, 2008).

\section{Experimental results}

\section{Analysis of vocal music performance}

With the intention of examining the influences of the online PA on students' vocal music performance, the analysis of covariance (ANCOVA) method was adopted using the pre-performing ratings as the covariate and the post-performing ratings as dependent variables. ANCOVA was performed after verifying that the regression did not violate the homogeneity test $(F=.65, p=.43>.05)$. Table 1 presents the ANCOVA results of the two groups. Based on the results, there were significant differences between the two groups in the vocal music performance $\left(F=16.21, p=.000<.001, \eta^{2}=.283\right)$. Moreover, the WSQ-based PA method had a significant impact on students' vocal music performance.

Table 1

The results of the ANCOVAs on students' vocal music performance

\begin{tabular}{lcccccc}
\hline Group & $N$ & Mean & $S D$ & Adjusted mean & $F$ & $\eta^{2}$ \\
\hline Experimental group & 22 & 17.28 & 0.73 & 17.36 & $16.21^{* * *}$ & .283 \\
Control group & 22 & 16.66 & 0.85 & 16.60 & & \\
\hline
\end{tabular}

${ }^{* * *} p<.001$

To further explain the results, we used ANCOVA to analyse the quality of vocal music performance according to the five dimensions of pitch accuracy, tonal centre, tempo, expression or phrasing and tone quality, as shown in Table 2. We examined the influences of the two teaching methods on the students' vocal music performance after analysing the quality based on the five dimensions. In the field of pitch accuracy $(F=5.88, p<.05)$, tonal centre $(F=4.31, p<.05)$, tempo consistency $(F=5.12, p<.05)$, musical phrase shaping $(F=4.37, p<.05)$ and tone quality $(F=4.11, p<.05)$, there were significant differences. Overall, the five dimensions used to examine the performance quality of vocal music performance showed a significant difference $(F=16.21, p<.001)$, indicating that the WSQ-based mobile PA assisted students in improving their vocal music performance.

Table 2

ANCOVA results analysing the scores of vocal music performance across the five dimensions

\begin{tabular}{|c|c|c|c|c|c|c|c|}
\hline Dimensions & Group & $N$ & Mean & $S D$ & Adjusted mean & $F$ & $\eta^{2}$ \\
\hline \multirow[t]{2}{*}{ Pitch accuracy } & Experimental group & 22 & 3.43 & 0.13 & 3.43 & $5.88^{*}$ & .125 \\
\hline & Control group & 22 & 3.32 & 0.18 & 3.32 & & \\
\hline \multirow{2}{*}{ Tonal centre } & Experimental group & 22 & 3.28 & 0.23 & 3.29 & $4.31^{*}$ & .095 \\
\hline & Control group & 22 & 3.15 & 0.24 & 3.14 & & \\
\hline \multirow[t]{2}{*}{ Tempo } & Experimental group & 22 & 3.32 & 0.23 & 3.32 & $5.12^{*}$ & .111 \\
\hline & Control group & 22 & 3.17 & 0.19 & 3.17 & & \\
\hline \multirow{2}{*}{$\begin{array}{l}\text { Expression or } \\
\text { phrasing }\end{array}$} & Experimental group & 22 & 3.61 & 0.18 & 3.62 & $4.37^{*}$ & .096 \\
\hline & Control group & 22 & 3.50 & 0.23 & 3.50 & & \\
\hline \multirow[t]{2}{*}{ Tone quality } & Experimental group & 22 & 3.64 & 0.18 & 3.64 & $4.11 *$ & .091 \\
\hline & Control group & 22 & 3.52 & 0.21 & 3.52 & & \\
\hline \multirow[t]{2}{*}{ Overall } & Experimental group & 22 & 17.28 & 0.73 & 17.36 & $16.21^{* * *}$ & .283 \\
\hline & Control group & 22 & 16.66 & 0.85 & 16.60 & & \\
\hline
\end{tabular}




\section{Analysis of learning attitude}

With the intention of examining the influences of the mobile PA on students' learning attitudes in the vocal music course, ANCOVA method was adopted using the pre-questionnaire on learning attitude as the covariate and the post-questionnaire as the dependent variable. ANCOVA was performed to analyse their learning attitudes after verifying that the regression did not violate the homogeneity test $(F=.262, p=$ $.611>.05)$. ANCOVA results reveal no significant differences between the two groups $(F=1.59, p=.22>$ $\left..05, \eta^{2}=.037\right)$, as shown in Table 3. The WSQ-based mobile PA did not assist students in changing their learning attitude towards vocal music.

Table 3

Results of ANCOVA on students' learning attitude

\begin{tabular}{llllll}
\hline Group & $N$ & Mean & $S D$ & Adjusted mean & $F$ \\
\hline Experimental group & 22 & 4.18 & 0.55 & 4.24 & 1.59 \\
Control group & 22 & 4.49 & 0.40 & 4.43 & \\
\hline
\end{tabular}

\section{Correlation analysis of peer and teacher scores in different modes}

In order to investigate the assessment quality difference between the experimental group and the control group, a correlation analysis of PA and expert assessment was conducted. Table 4 shows a correlation analysis between the PA and expert assessments for each dimension in the experimental and control groups over the 5 weeks. The results of the experimental group clearly show that four out of five coefficients $(r)$, which ranged from .42 to .72, are highly correlated. It can be inferred that students using the WSQ-based mobile PA method may have assessment skills more similar to experts, compared with the control group. However, there were no significant correlations between all evaluating items listed in the control group; this may be because they did not give rigorous comments when compared with those given by the teacher, leading to no correlation between their assessment (C.-C. Chang et al., 2012). It may be that the WSQbased learning sheet allow evaluators to pay more attention to the standard of the rubrics, which assists them in providing PA by using the main point from the written record on the learning sheet.

Table 4

Correlation analysis of PA and expert assessment

\begin{tabular}{|c|c|c|c|c|c|}
\hline Group & Assessment items & Measure & $M$ & $S D$ & $r$ \\
\hline \multirow{10}{*}{$\begin{array}{l}\text { Experimental } \\
\text { group } \\
(N=22)\end{array}$} & \multirow[t]{2}{*}{ Pitch accuracy } & Peers & 3.42 & 0.29 & \multirow[t]{2}{*}{$.574 * *$} \\
\hline & & Experts & 3.11 & 0.38 & \\
\hline & \multirow[t]{2}{*}{ Tonal centre } & Peers & 3.34 & 0.32 & \multirow[t]{2}{*}{.16} \\
\hline & & Experts & 2.96 & 0.33 & \\
\hline & \multirow[t]{2}{*}{ Tempo } & Peers & 3.48 & 0.27 & \multirow[t]{2}{*}{$.575^{* *}$} \\
\hline & & Experts & 3.20 & 0.42 & \\
\hline & \multirow[t]{2}{*}{ Expression or phrasing } & Peers & 3.35 & 0.33 & \multirow[t]{2}{*}{$.423 *$} \\
\hline & & Experts & 2.96 & 0.27 & \\
\hline & \multirow[t]{2}{*}{ Tone quality } & Peers & 3.66 & 0.33 & \multirow[t]{2}{*}{$.721 * *$} \\
\hline & & Experts & 3.39 & 0.29 & \\
\hline \multirow{10}{*}{$\begin{array}{l}\text { Control group } \\
(N=22)\end{array}$} & \multirow{2}{*}{ Pitch accuracy } & Peers & 3.57 & 0.16 & \multirow[t]{2}{*}{-.196} \\
\hline & & Experts & 2.97 & 0.20 & \\
\hline & \multirow[t]{2}{*}{ Tonal centre } & Peers & 3.40 & 0.19 & \multirow[t]{2}{*}{-.072} \\
\hline & & Experts & 2.86 & 0.20 & \\
\hline & \multirow[t]{2}{*}{ Tempo } & Peers & 3.64 & 0.13 & \multirow[t]{2}{*}{.028} \\
\hline & & Experts & 3.18 & 0.21 & \\
\hline & \multirow[t]{2}{*}{ Expression or phrasing } & Peers & 3.46 & 0.13 & \multirow[t]{2}{*}{-.069} \\
\hline & & Experts & 3.11 & 0.22 & \\
\hline & \multirow[t]{2}{*}{ Tone quality } & Peers & 3.59 & 0.16 & \multirow[t]{2}{*}{.204} \\
\hline & & Experts & 3.55 & 0.15 & \\
\hline
\end{tabular}

$* p<.05, * * p<.01$ 


\section{Interview results}

In the interview, students mentioned that there were many learning benefits when combining the WSQbased strategies with PA. Students from the experimental group mentioned three benefits, namely "effective and useful strategies", "improving vocal music performance" and "promoting the understanding of vocal music-related theories". To refer to students, we used the letters " $E$ " and "C" to describe their group (experimental or control) and a number. For example, E28 represents a student in the experimental group with the number 28 .

The following quotes refer to "effective and useful strategies":

I used to take notes in the language lessons, but the WSQ-based learning sheet allows me to better organise the course notes on vocal music. (E28)

Written notes are more reliable than listening and memorising. Moreover, I will initially search for information and ask the teacher during class if I don't understand anything listed in the WSQ. (E37)

There was a lot of vocal knowledge in the WSQ-based learning sheet that I had not come across before. I could objectively assess others' vocal singing skills from the perspective of the reviewer after the teacher explained the rubrics. (E25)

The following quotes refer to "improving vocal music performance":

I made great progress during the 5 weeks. I can preview the teaching videos in advance and fill out the WSQ-based learning sheet. Questions related to the teaching videos will be addressed and explained by teachers in class. After school, I kept repeatedly practising and recording videos and assessed peers' work. All these allowed me to properly integrate intellectual understanding and practical knowledge in vocal music. (E32)

Although the WSQ-based mobile peer-assessment did take lots of time and effort, it gave me unexpected achievements by following the teacher's steps in the 5 consecutive weeks. (E35)

The following quotes refer to "promoting the understanding of vocal music-related theories":

I used to know how to sing but didn't understand the vocal position of the vocal music and its theories. Now I'm not only able to evaluate the level of vocal performance, but I can also know what's going on and the reasons behind it. (E36)

The main point of vocal practice can be clearly visualised through WSQ, either in text or pictures. I made adjustments and reflections while practising, aiming at deepening my understanding of vocal skills, methods and principles. (E47)

Students from the control group indicated that the main advantages of using mobile PA are "promoting reflection", "shortcomings can be easily discovered" and "having more responsibility".

The following quotes refer to "promoting reflection":

I will make a comparison of my video, those with high scores and the teacher's videos when I see the scores given by peers. I will also make a reflection to seek the reasons for mark deduction and memorise my problems so that I can figure out the solutions. (C20)

The following quotes refer to "shortcomings can be easily discovered":

I can hear peers' vocal music, learn their advantages and reflect on my shortcomings as well as enhance my sense of music when I observe their videos during assessment. (C03) 
I will record more than once when recording weekly videos as I can discover my shortcomings and amend them through repeatedly recording. Sometimes, I will compare my videos with the teachers' videos and aim at seeking improvements. (C14)

The following quotes refer to "having more responsibility":

I will force myself to practise in the piano room whenever I have time because I have to upload weekly video-based assignments in Mosoteach. (C14)

With regard to the videos uploaded by teachers in Mosoteach before the lesson, they will include singing processes and illustration of the theoretical knowledge. I will actively search for information online if I want to understand relevant concepts. (C18)

\section{Conclusions}

Technology-supported music education has received considerable attention in recent years. In the field of vocal music education, studies with proper technology to innovate the pedagogy have been lacking. In this study, we conducted an experiment for 5 weeks in a university to examine the effectiveness of WSQ-based mobile PA in a vocal music course. Learners' vocal music performance and their learning attitudes were examined. Moreover, we carried out further analysis of students' perceptions of using the WSQ-based mobile PA through conducting interviews. Through comparing the peer and expert assessments, we were able to analyse the learners' assessment quality in the learning process.

\section{Discussion}

The results of the experiment indicate that students who used the WSQ-based mobile PA significantly enhanced their vocal music performance. Their learning attitudes, however, did not show enhancement. In other words, WSQ-based mobile PA is a learning method that can improve students' vocal music performance rather than their learning attitudes. Referring to the improvement of vocal music performance, WSQ can give students scaffolding during the learning activities. Similar to a study that adopted the WSQ approach for a dance course (Hsia et al., 2019), a significant effect of the WSQ approach on learning performance was found. Through the interview results, the strengths of the WSQ approach can also be understood. Students stated that filling out the WSQ learning sheets enhanced their ability to actively organise the theoretical vocal music knowledge and encouraged them to reflect on which parts confused them. This corresponds to a statement of scholars in art education (Brown \& Walter, 2014; Lai \& Hwang, 2015), that proper strategies benefit learners by helping them engage actively and think deeply. With appropriate strategies, PA has great potential to innovate art education.

With regard to learning attitudes, there was no significant difference between the experimental and control groups. Similar to the study of Hilton and Christensen (2002), which evaluated the influence of multimedia on students' learning attitudes in a statistics course, multimedia did not improve the students' learning attitudes. Another study which found similar results of insignificant impacts on students (Hsia et al., 2019) gave a possible explanation that the vocal music course is skill-oriented rather than being an academic subject. Students' learning attitudes towards vocal music learning are more relaxed and generally free of learning anxiety and rating pressure; thus, learning attitudes are not easily changed in a short time. Thus, researchers in music education may consider prolonging the experiment duration. From the interview results, another possible reason may be that the content of the WSQ learning sheets required students to spend more time searching for related information, summarising the learning points and reflecting to pose questions, which may cause a certain degree of learning anxiety and upset students. Updated WSQ learning sheets and a revised learning format for vocal music education are strongly needed.

The quality of PA during the learning process also attracted considerable attention in the current study. Lai and Hwang (2015) have pointed out the necessity of improving learners' assessment quality to promote their learning achievement. Thus, a correlation analysis between PA and expert assessment was conducted. The results indicate that the assessment of students using WSQ-based mobile PA is more correlated with the assessment of experts. This means that WSQ-based mobile PA not only significantly impacted the learners' vocal music skills but also helped to improve their assessment ability. Through the qualitative 
analysis of the interview data, the strengths of the WSQ strategies can also be understood. WSQ is an effective scaffolding strategy, especially the question posing which guided the learners to reflect in depth. All of these results have confirmed the significance of WSQ-based mobile PA for improving students' vocal music skills.

\section{Implications for pedagogy and practice}

This study integrated WSQ-based learning sheets as a support in a vocal music course and found that it effectively improved the students' vocal skills. There are implications for vocal music teachers and researchers. The first implication is innovating vocal music pedagogy. The vocal music course emphasises repeated practice and skill improvement, and technology has rarely been introduced to assist teaching vocal music. The application of the WSQ-based learning sheet combined with online teaching videos and offline tutorial teaching helped the students integrate knowledgeable theories into real practice. This study may be encouraging for music or art education teachers to integrate proper technology and strategies into their daily teaching. In addition, students can gain a systematic understanding of the terminology and related theoretical principles of vocal music with the help of WSQ learning sheets. This may provoke music teachers or art education teachers to think about other information technologies to adapt to learners' needs. The research results may also be beneficial for researchers or educational music app designers to develop more efficient instruments to scaffold the learning process.

\section{Limitations and future directions}

There also exist limitations in this study that should be noted. First of all, the sampling size was limited because, in vocal music courses, it is difficult to guarantee the teaching efficiency if the class size is too big. Secondly, considering the particular features (skill-oriented learning and learning and improvising performance) of the current study, the findings may not be generalisable to other courses. Moreover, the results indicate that the WSQ-based mobile PA did not have a significant impact on the students' learning attitude. This may be because traditional vocal music courses are conducted face-to-face to address and solve students' questions immediately; students may feel overloaded when involved in the WSQ-based mobile learning activities. Thus, to benefit students' vocal music learning with the support of technology, students' technology acceptance and the curriculum design should be taken into consideration. In future, it would therefore be worth broadening and applying the current method to more fields of music education. There is a strong need to explore more technology instruments and teaching strategies for vocal music or related domains in order to enhance students' learning achievement and their learning attitudes.

\section{Acknowledgements}

This study is supported in part by the Education Science Strategic Planning Office of Zhejiang Province in China, under contract number RZ2007007P.

\section{References}

Boud, D., Cohen, R., \& Sampson, J. (1999). Peer learning and assessment. Assessment Evaluation in Higher Education, 24, 413-426. https://doi.org/10.1080/0260293990240405

Brown, S. I., \& Walter, M. I. (2014). Problem posing: Reflections and applications. Psychology Press.

Carlson, P. A., \& Berry, F. C. (2008). Using computer-mediated peer review in an engineering design course. IEEE Transactions on Professional Communication, 51(3), 264-279. https://doi.org/10.1109/tpc.2008.2001254

Chang, C., \& Lin, H. (2019). Effects of a mobile-based peer-assessment approach on enhancing language-learner' oral proficiency. Innovations in Education Teaching International, 57, 668- 679. https://doi.org/10.1080/14703297.2019.1612264

Chang, C.-C., Tseng, K.-H., \& Lou, S.-J. (2012). A comparative analysis of the consistency and difference among teacher-assessment, student self-assessment and peer-assessment in a Web-based portfolio assessment environment for high school students. Computers \& Education, 58(1), 303-320. https://doi.org/10.1016/j.compedu.2011.08.005 
Chen, H.-R., \& Huang, H.-L. (2010). User acceptance of mobile knowledge management learning system: design and analysis. Journal of Educational Technology \& Society, 13(3), 70-77. https://drive.google.com/open?id=12C0rzT8PTj8_fkC0HBRG-44rmRX_JgHv

Chen, I. C., Hwang, G. J., Lai, C. L., \& Wang, W. C. (2020). From design to reflection: Effects of peerscoring and comments on students' behavioral patterns and learning outcomes in musical theater performance. Computers \& Education, 150, 103856. https://doi.org/10.1016/j.compedu.2020.103856

Chien, S., Hwang, G., \& Jong, M. S. Y. (2020). Effects of peer assessment within the context of spherical video-based virtual reality on EFL students' English-speaking performance and learning perceptions. Computers \& Education, 146, Article 103751. https://doi.org/10.1016/j.compedu.2019.103751

Clipa, O., Ignat, A.-A., \& Rusu, P. (2011). Relations of self-assessment accuracy with motivation level and metacognition abilities in pre-service teacher training. Procedia-Social Behavioral Sciences, 30, 883-888. https://doi.org/10.1016/J.SBSPRO.2011.10.171

Demorest, S., Nichols, B., \& Pfordresher, P. Q. (2018). The effect of focused instruction on young children's singing accuracy. Psychology of Music, 46(4), 488-499. https://doi.org/10.1177/0305735617713120

Denton, P., Madden, J., Roberts, M., \& Rowe, P. (2008). Students' response to traditional and computerassisted formative feedback: A comparative case study. British Journal of Educational Technology, 39(3), 486-500. https://doi.org/10.1111/j.1467-8535.2007.00745.x

Ericsson, K. A., Krampe, R. T., \& Tesch-Römer, C. (1993). The role of deliberate practice in the acquisition of expert performance. Psychological Review, 100(3), 363-406. https://doi.org/10.1037/0033-295X.100.3.363

Gallo, D. J. (2019). Formative assessment practices and children's singing accuracy: A mixed methods inquiry. International Journal of Music Education, 37(4), 593-607. https://doi.org/10.1177/0255761419852172

Gaunt, H. (2008). One-to-one tuition in a conservatoire: The perceptions of instrumental and vocal teachers. Psychology of Music, 36(2), 215-245. https://doi.org/10.1177/0305735607080827

Griffiths, M., \& Woolf, F. (2009). The Nottingham apprenticeship model: Schools in partnership with artists and creative practitioners. British Educational Research Journal, 35(4), 557-574. https://doi.org/10.1080/01411920802045492

Hewitt, M. P. (2011). The impact of self-evaluation instruction on student self-evaluation, music performance, and self-evaluation accuracy. Journal of Research in Music Education, 59(1), 6-20. https://doi.org/10.1177/0022429410391541

Hilton, S. C., \& Christensen, H. B. (2002). Evaluating the impact of multimedia lectures on student learning and attitudes: Developing a statistically literate society. In Proceedings of the Sixth International Conference on Teaching of Statistics (pp. 1-6). International Association for Statistical Information. http://iase-web.org/documents/papers/icots6/6f3 hilt.pdf

Hobbs, R. (2006). Non-optimal uses of video in the classroom. Learning, Media and Technology, 31(1), 35-50. https://doi.org/10.1080/17439880500515457

Hsia, L.-H., \& Hwang, G. J. (2020). From reflective thinking to learning engagement awareness: A reflective thinking promoting approach to improve students' dance performance, self-efficacy and task load in flipped learning. British Journal of Educational Technology, 51(6), 2461-2477. https://doi.org/10.1111/bjet.12911

Hsia, L.-H., Hwang, G.-J., \& Lin, C.-J. (2019). A WSQ-based flipped learning approach to improving students' dance performance through reflection and effort promotion. Interactive Learning Environments. https://doi.org/10.1080/10494820.2019.1651744

Hung, Y., Samuelson, B. L., \& Chen, S. (2016). Relationships between peer- and self-assessment and teacher assessment of young EFL learners' oral presentations. In M. Nikolov (Ed.), Educational linguistics: Vol. 25. Assessing young learners of English: Global and local perspectives (pp. 317 338). Springer. https://doi.org/10.1007/978-3-319-22422-0_13

Hwang, G.-J., \& Chang, H.-F. (2011). A formative assessment-based mobile learning approach to improving the learning attitudes and achievements of students. Computers \& Education, 56(4), 10231031. https://doi.org/10.1016/j.compedu.2010.12.002

Hwang, G.-J., Hung, C.-M., \& Chen, N.-S. (2014). Improving learning achievements, motivations and problem-solving skills through a peer assessment-based game development approach. Educational Technology Research and Development, 62(2), 129-145. https://doi.org/10.1007/s11423-013-9320-7

Hwang, G.-J., Wu, P.-H., \& Ke, H.-R. (2011). An interactive concept map approach to supporting mobile learning activities for natural science courses. Computers \& Education, 57(4), 2272-2280. https://doi.org/10.1016/j.compedu.2011.06.011 
Hwang, G.-J., Yang, T.-C., Tsai, C.-C., \& Yang, S. J. H. (2009). A context-aware ubiquitous learning environment for conducting complex science experiments. Computers \& Education, 53(2), 402-413. https://doi.org/10.1016/j.compedu.2009.02.016

Kirch, C. (2012). WSQing. Flipping with Kirch. http://flippingwithkirch.blogspot.com/p/wsqing.html

Lai, C.-L., \& Hwang, G.-J. (2015). An interactive peer-assessment criteria development approach to improving students' art design performance using handheld devices. Computers \& Education, 85, 149-159. https://doi.org/10.1016/j.compedu.2015.02.011

Latukefu, L. (2010). Peer assessment in tertiary level singing: Changing and shaping culture through social interaction. Research Studies in Music Education, 32(1), 61-73. https://doi.org/10.1177/1321103X10370091

Lavrakas, P. J. (2008). Encyclopedia of survey research methods. Sage Publications. https://doi.org/10.4135/9781412963947.n337

Lehmann, A. C. (2015). The acquisition of expertise in music: Efficiency of deliberate practice as a moderating variable in accounting for sub-expert performance. In I. Deliege \& J. A. Sloboda (Eds.), Perception and cognition of music (pp. 161-187). Taylor \& Francis.

Li, D. (2015). New 'field' of vocal music teaching and research: Research on the construction of a novel interaction mode. English Language Teaching, 8(12), 74-78. https://doi.org/10.5539/ELT.V8N12P74

Li, Z. (2017). Design of online vocal music course based on Azure-PaaS platform. International Journal of Emerging Technologies in Learning, 12(9), 17-27. https://online-journals.org/index.php/ijet/article/view/7495/4588

Lin, H. C., Hwang, G. J., \& Hsu, Y. D. (2019). Effects of ASQ-based flipped learning on nurse practitioner learners' nursing skills, learning achievement and learning perceptions. Computers \& Education, 139, 207-221. https://doi.org/10.1016/j.compedu.2019.05.014

Liu, E. Z.-F., \& Lin, S. S. J. (2007). Relationship between peer feedback, cognitive and metacognitive strategies and achievement in networked peer assessment. British Journal of Educational Technology, 38(6), 1122-1125. https://doi.org/10.1111/j.1467-8535.2007.00702.x

Matsuno, S. (2009). Self-, peer-, and teacher-assessments in Japanese university EFL writing classrooms. Language Testing, 26(1), 75-100. https://doi.org/10.1177/0265532208097337

Neokleous, R. (2015). Aiming for the singing teacher: An applied study on preservice kindergarten teachers' singing skills development within a music methods course. International Journal of Music Education, 33(2), 163-180. https://doi.org/10.1177/0305735607080827

Paney, A. S., \& Kay, A. C. (2015). Developing singing in third-grade music classrooms: The effect of a concurrent-feedback computer game on pitch-matching skills. Update: Applications of Research in Music Education, 34(1), 42-49. https://doi.org/10.1177/8755123314548047

Rutkowski, J., \& Miller, M. S. (2003). The effect of teacher feedback and modeling on first graders' use of singing voice and developmental music aptitude. Bulletin of the Council for Research in Music Education, 156, 1-10. http://www.jstor.org/stable/40319169

Santagata, R., Zannoni, C., \& Stigler, J. W. (2007). The role of lesson analysis in pre-service teacher education: An empirical investigation of teacher learning from a virtual video-based field experience. Journal of Mathematics Teacher Education, 10, 123-140. https://doi.org/10.1007/s10857-007-9029-9

Searby, M., \& Ewers, T. (1997). An evaluation of the use of peer assessment in higher education: A case study in the School of Music, Kingston University. Assessment Evaluation in Higher Education, 22, 371-383. https://doi.org/10.1080/0260293970220402

Svec, C. L. (2018). The effects of instruction on the singing ability of children ages 5 to 11: A metaanalysis. Psychology of Music, 46(3), 326-339. https://doi.org/10.1177/0305735617709920

Swaffield, S. (2011). Getting to the heart of authentic assessment for learning. Assessment in Education: Principles, Policy \& Practice, 18(4), 433-449. https://doi.org/10.1080/0969594X.2011.582838

Tai, H.-C., Lin, W., \& Yang, S. C. (2015). Exploring the effects of peer review and teachers' corrective feedback on EFL students' online writing performance. Journal of Educational Computing Research, 53, 284-309. https://doi.org/10.1177/0735633115597490

Thornton, L. C. (2008). The effect of grade, experience, and listening condition on the melodic error detection of fifth-and sixth-grade woodwind students. Update: Applications of Research in Music Education, 26(2), 4-10. https://doi.org/10.1177/8755123308317612

Topping, K. (1998). Peer assessment between students in colleges and universities. Review of Educational Research, 68, 249-276. https://doi.org/10.3102/00346543068003249

Tsai, C.-C., \& Liang, J.-C. (2009). The development of science activities via on-line peer assessment: the role of scientific epistemological views. Instructional Science, 37(3), 293-310.

https://doi.org/10.1007/s11251-007-9047-0 
Tseng, S.-C., \& Tsai, C.-C. (2007). On-line peer assessment and the role of the peer feedback: A study of high school computer course. Computers \& Education, 49(4), 1161-1174. https://doi.org/10.1016/j.compedu.2006.01.007

Tseng, S.-C., \& Tsai, C.-C. (2010). Taiwan college students' self-efficacy and motivation of learning in online peer assessment environments. Internet and Higher Education, 13(3), 164-169. https://doi.org/10.1016/j.iheduc.2010.01.001

Tsivitanidou, O. E., Zacharia, Z. C., \& Hovardas, T. (2011). Investigating secondary school students' unmediated peer assessment skills. Learning and Instruction, 21(4), 506-519. https://doi.org/10.1016/j.learninstruc.2010.08.002

Wu, C.-C., \& Kao, H.-C. (2008). Streaming videos in peer assessment to support training pre-service teachers. Journal of Educational Technology \& Society, 11(1), 45-55. https://drive.google.com/file/d/1EKbeyz bYkpIJ2NT3gGh8P-c2GlwVGnK/view

Wu, P.-H., Hwang, G.-J., Milrad, M., Ke, H.-R., \& Huang, Y.-M. (2012). An innovative concept map approach for improving students' learning performance with an instant feedback mechanism. British Journal of Educational Technology, 43(2), 217-232. https://doi.org/10.1111/j.14678535.2010.01167.x

Yilmaz, R. (2017). Exploring the role of e-learning readiness on student satisfaction and motivation in flipped classroom. Computers in Human Behavior, 70, 251-260.

https://doi.org/10.1016/j.chb.2016.12.085

Corresponding author: Youmei Wang, wangyoumei@126.com

Copyright: Articles published in the Australasian Journal of Educational Technology (AJET) are available under Creative Commons Attribution Non-Commercial No Derivatives Licence (CC BY-NC-ND 4.0). Authors retain copyright in their work and grant AJET right of first publication under CC BY-NC-ND 4.0.

Please cite as: Wang, Y, Wan, P., Tu, Y.-F., Chen, K., \& Liu, C. (2021). A WSQ-based mobile peer assessment approach to enhancing university students' vocal music skills and learning perceptions. Australasian Journal of Educational Technology, 37(6), 1-17. https://doi.org/10.14742/ajet.6832 


\section{Appendix}

Vocal music rubric for the vocal music program

\begin{tabular}{|c|c|c|c|c|}
\hline $\begin{array}{l}\text { Assessment } \\
\text { items }\end{array}$ & 4 & 3 & 2 & 1 \\
\hline Pitch accuracy & $\begin{array}{l}\text { The student sings } \\
\text { all pitches } \\
\text { accurately. }\end{array}$ & $\begin{array}{l}\text { The student sings } \\
\text { most pitches } \\
\text { accurately. Errors } \\
\text { do not detract from } \\
\text { overall } \\
\text { performance. }\end{array}$ & $\begin{array}{l}\text { The student sings } \\
\text { some pitches } \\
\text { accurately. } \\
\text { Errors detract from } \\
\text { overall } \\
\text { performance. }\end{array}$ & $\begin{array}{l}\text { The student sings } \\
\text { few or no pitches } \\
\text { accurately. }\end{array}$ \\
\hline Tonal centre & $\begin{array}{l}\text { The student } \\
\text { maintains the tonal } \\
\text { centre. }\end{array}$ & $\begin{array}{l}\text { The student } \\
\text { deviates little from } \\
\text { the tonal centre. }\end{array}$ & $\begin{array}{l}\text { The student } \\
\text { deviates once from } \\
\text { the tonal centre } \\
\text { (includes deviating } \\
\text { once and returning } \\
\text { to the original } \\
\text { key). }\end{array}$ & $\begin{array}{l}\text { The student } \\
\text { deviates } 2 \text { or more } \\
\text { times from the } \\
\text { tonal centre. }\end{array}$ \\
\hline Tempo & $\begin{array}{l}\text { The student } \\
\text { maintains } \\
\text { appropriate tempo } \\
\text { or rhythm. }\end{array}$ & $\begin{array}{l}\text { The student } \\
\text { maintains } \\
\text { consistent tempo } \\
\text { or rhythm }\end{array}$ & $\begin{array}{l}\text { Some regularity in } \\
\text { tempo or rhythm, } \\
\text { but sometimes } \\
\text { misses }\end{array}$ & $\begin{array}{l}\text { Tempo is uncertain } \\
\text { and irregular. }\end{array}$ \\
\hline $\begin{array}{l}\text { Expression or } \\
\text { phrasing }\end{array}$ & $\begin{array}{l}\text { Expression } \\
\text { enhances } \\
\text { performance by } \\
\text { adding appropriate } \\
\text { depth and } \\
\text { emotional range. }\end{array}$ & $\begin{array}{l}\text { Expression is } \\
\text { generally } \\
\text { appropriate to the } \\
\text { song being sung. }\end{array}$ & $\begin{array}{l}\text { Expression is } \\
\text { partially } \\
\text { appropriate but } \\
\text { may be } \\
\text { inconsistent. }\end{array}$ & $\begin{array}{l}\text { Monotonic or } \\
\text { inappropriate } \\
\text { expression. }\end{array}$ \\
\hline Tone quality & $\begin{array}{l}\text { The student } \\
\text { performs using a } \\
\text { light treble head } \\
\text { voice, clear tone } \\
\text { quality and breath } \\
\text { support } \\
\text { throughout. }\end{array}$ & $\begin{array}{l}\text { The student always } \\
\text { performs using a } \\
\text { light treble head } \\
\text { voice, clear tone } \\
\text { quality and breath } \\
\text { support } \\
\text { throughout. }\end{array}$ & $\begin{array}{l}\text { The student } \\
\text { sometimes } \\
\text { performs with a } \\
\text { light treble head } \\
\text { voice, clear tone } \\
\text { quality and breath } \\
\text { support. Errors } \\
\text { detract from } \\
\text { performance. }\end{array}$ & $\begin{array}{l}\text { The student rarely } \\
\text { sings with a light } \\
\text { treble head voice } \\
\text { or only uses a } \\
\text { speaking voice. }\end{array}$ \\
\hline
\end{tabular}

\section{Interview questions after learning activities}

1. What is the difference between the current learning method and your previous learning experience? Please list and explain the knowledge and skills acquired during the learning process.

2. In general, what is your attitude towards this learning method?

3. What are the advantages of WSQ-based learning activities for you?

4. In your opinion, does the WSQ-based learning sheet need to be improved?

5. When this learning activities ends, would you like to use this learning method? If yes, tell us in which subject you expect to use it. If no, give us the reasons.

6. Would you like to recommend that other students use this learning method?

7. Would you like to recommend that other teachers use this instructional method? 